\title{
QUULLITY IN LEARNING AND TEACHING
}

Associate Professor Julie Fleming, Central Queensland University Associate Professor Kogi Naidoo, Charles Sturt University 


\section{INTRODUCTIONS}

- Who we are?

- Why are we here?

Invitation from Higher Education Services

- What are we focusing on?

Quality in Learning and Teaching

Achieved through academic staff PD and CPD

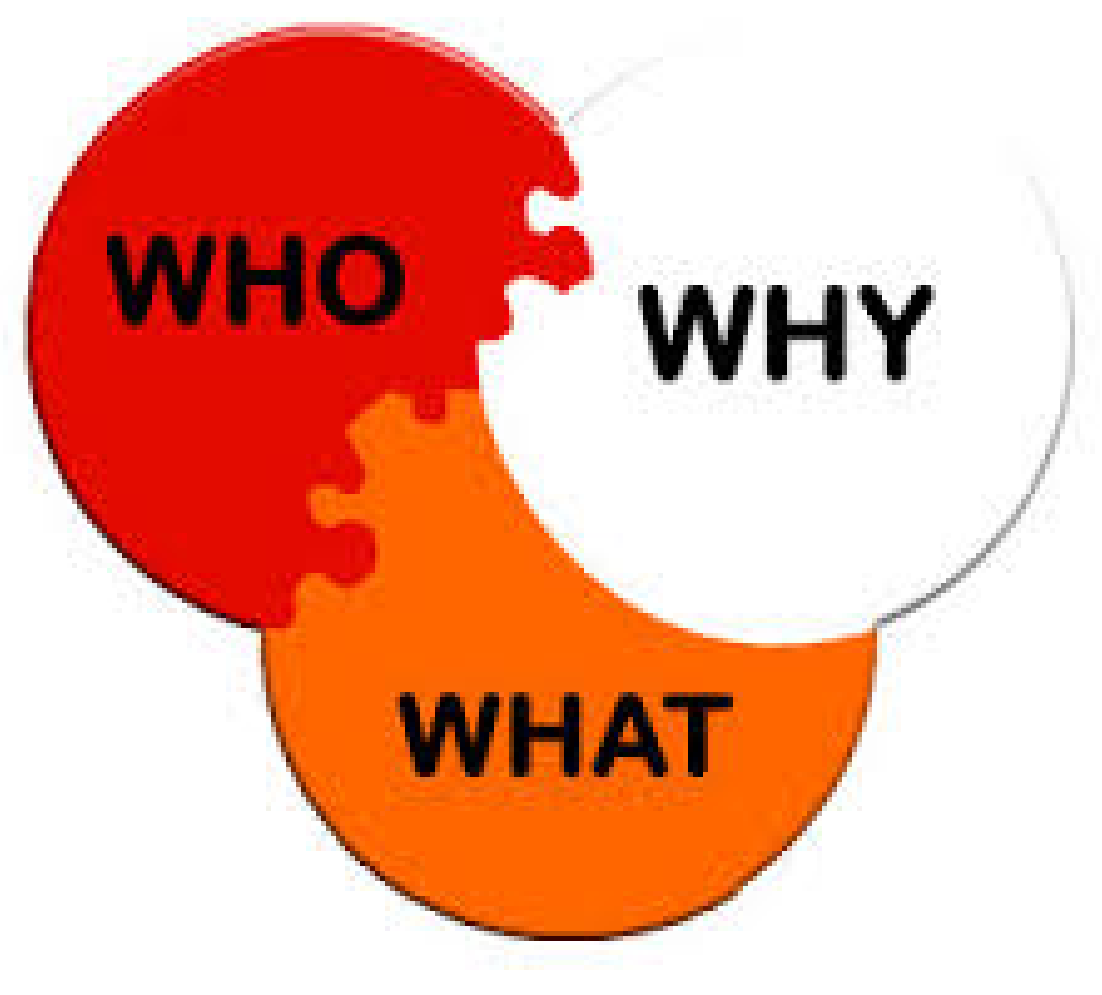




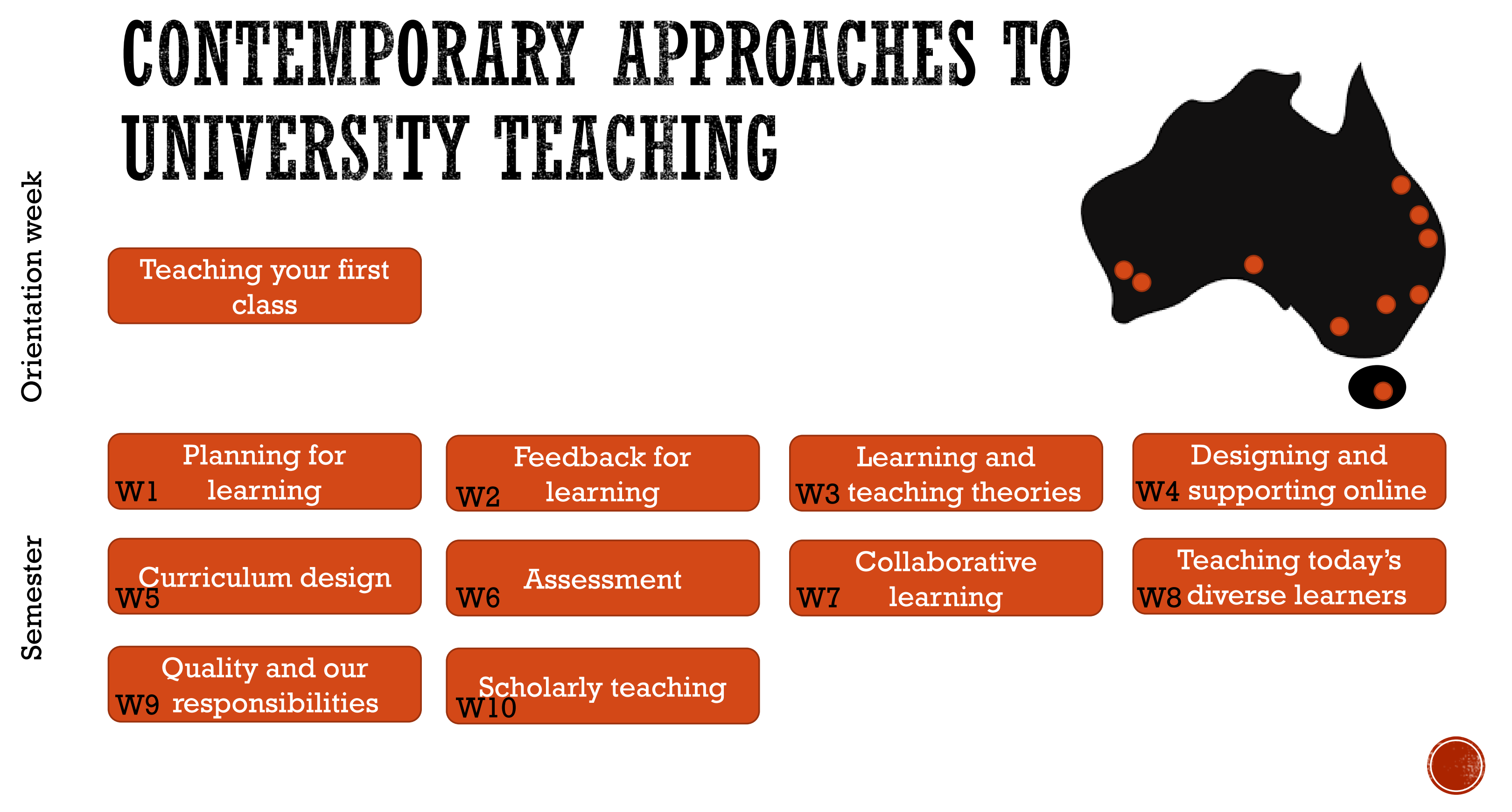




\section{QUALITY MIODULE}

- Examine the legislative requirement in which Australian higher education institutions operate;

- Access institutional policies and procedures relevant to your role as an educator;

- Consider institutional, program and unit level data to inform and assure standards; and

- Plan for your future professional development, using a professional standards framework.

- Our module: https://www.coursesites.com 


\section{QUALITY AND CONTINUOUS IMPROVEMENT}

The 6 rights for program quality:

- Right program level outcomes [including external reference points];

- Right mapping;

- Right assessment;

- Right grading;

- Right calibration; and

- Right learning methods and resources.

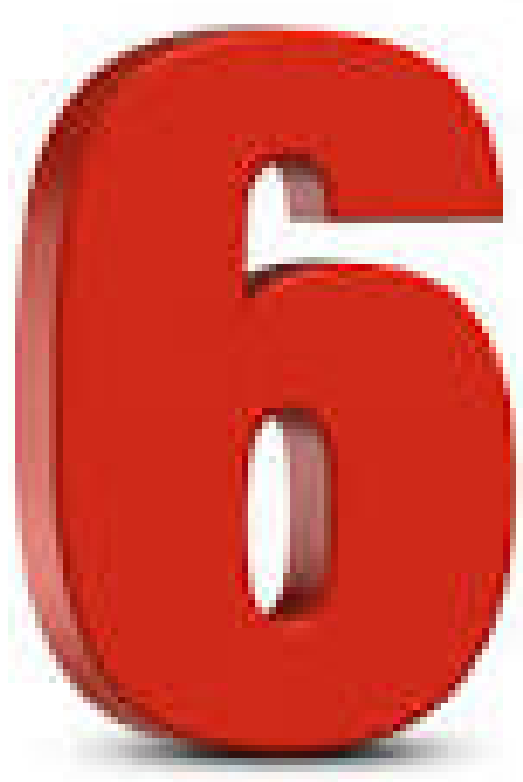




\section{INSTITUTIONAL QUHLITY}

- Adequate and reliable learning infrastructure

- Quality of teaching staff

- Unit design

- Quality management of assessments

- Administrative issues such as admissions and enrolment

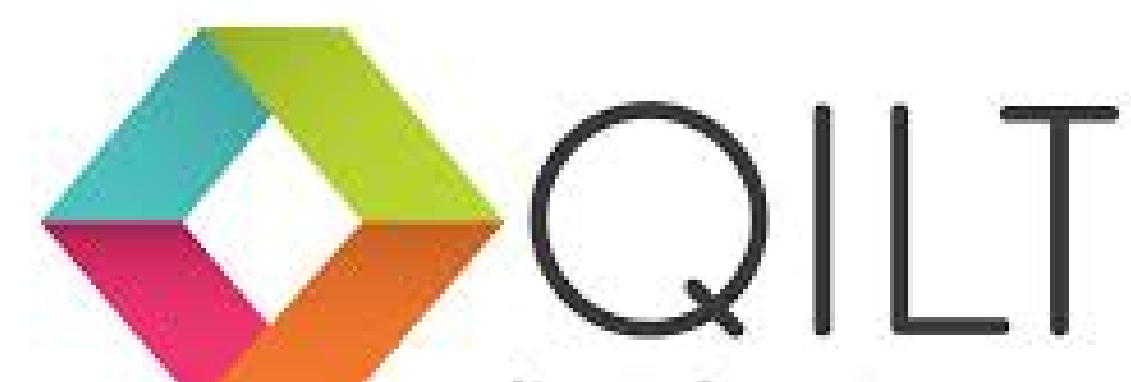

quality in learning \& teaching 


\section{CONTINUING PROFLSSIONAL DEVELOPIIENT}

- Australian University Teaching and Criteria Standards Framework

- Higher Education Academy (UK) Professional Standards Framework

- Higher Education Research and Development Society of Australasia

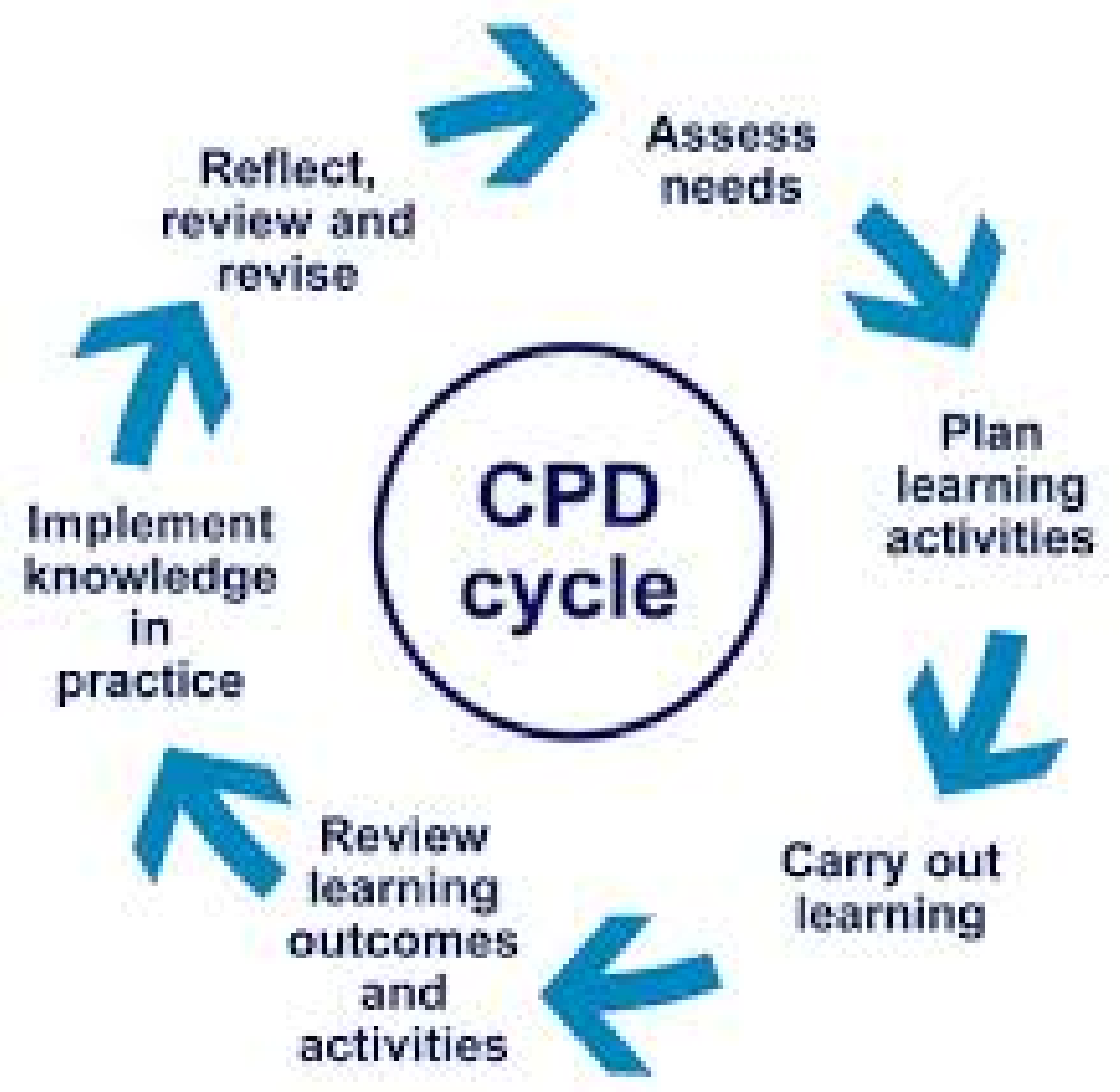




\section{MAINTAINING YOUR KNOWLEDGE}

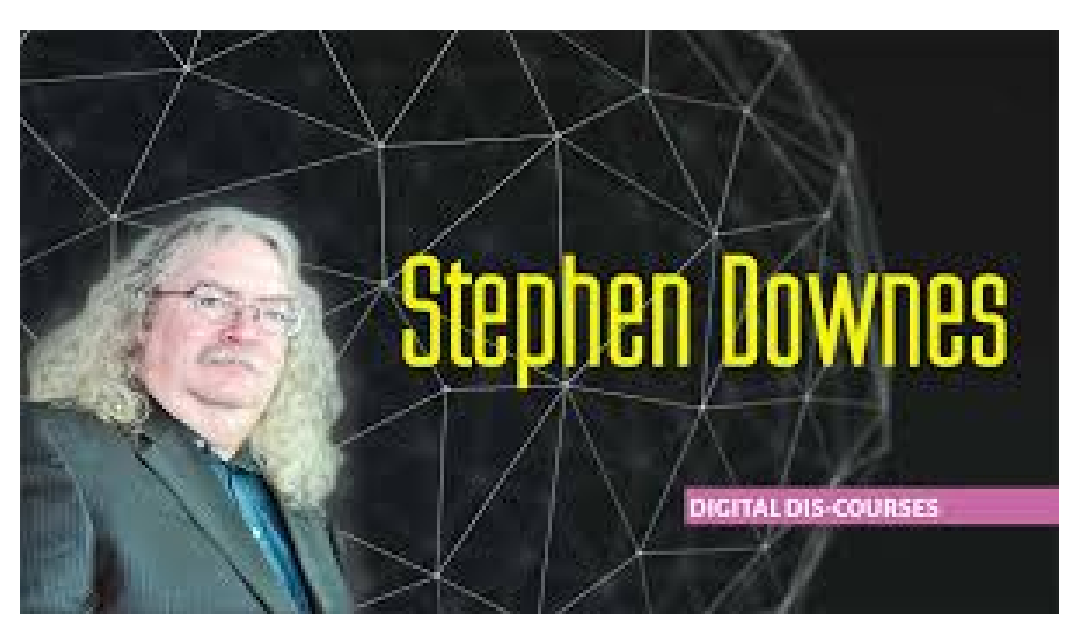

\section{THE CONVERSATION}

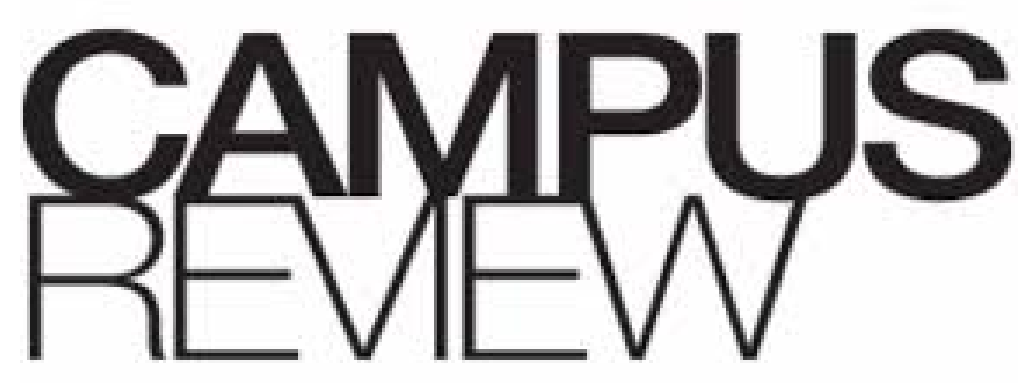




\section{QUHLITY IS EVERYONE'S BUSINESS}

- In Conclusion...

- Need for curriculum quality assurance, monitoring and continuous improvement

- The whole is greater than the sum of its parts...

Systems, Infrastructure, Staff (CPD), including SOTL

- Let's reward our teaching staff...

Reward and recognition policies aligned to career development 
QUESTIONS... 


\section{CONTACT US...}

Associate Professor Julie Fleming Associate Dean Learning \& Teaching CQUniversity

Bruce Hwy, North Rockhampton, QLD Email:j.fleming@cqu.edu.au Tel: 0749306969
Associate Professor Kogi Naidoo Director, Learning Academy

Charles Sturt University Boorooma St, Wagga Wagga, NSW

Email: knaidoo@csu.edu.au Tel: 0269334804

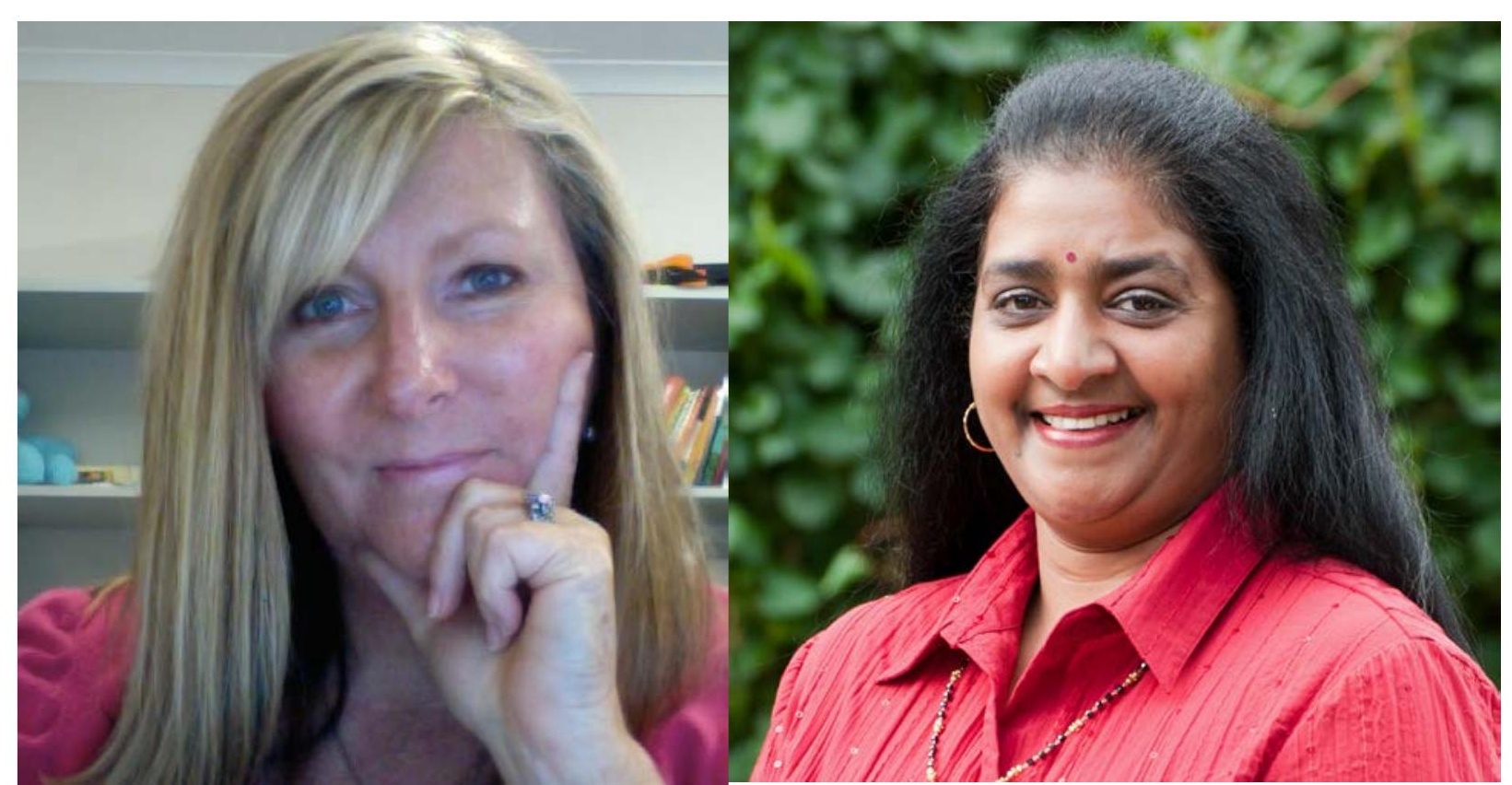

